\title{
Finite Element Analysis on Flexible Flange Joint of Steel Tubular Structure
}

\author{
Yangli WANG ${ }^{a}$, Rui YAN \\ Science College, Engineering University of Armed Police Force, Xi'an 710086, China \\ awzq93@163.com
}

Keywords: Steel Tube Tower, Flexible Flange, FEA, Strength; Bearing Capacity

\begin{abstract}
Flange joints are common in electric transmission steel tube tower. Flange with stiffening rib usually used, whose structure is complicated and do not meet the economic requirements, but flexible flanges make up the shortcoming in a certain state. So strength of flexible flanges subjected to axial force is studied by a program of finite element simulation analysis, which considered contact nonlinear problem of the bolt and flange. Then the influences of distance between bolts and tube, distance between bolts and edge of flanges, thickness of flanges, bolt number and bolt pretension on bearing capacity of flexible flange are investigated. Next the comparison of model test and finite element simulation analysis show the model accuracy. Finally, through analyzing of different simulation results, it turns out that the model has an adequate safety reserve and The variation of model parameters, such as distance between bolts and edge of flanges, thickness of flanges, bolt number and bolt pretension, can improve bearing capacity of flexible flange which provides a reference for application to the project.
\end{abstract}

\section{Introduction}

Steel tube tower transmission compared with angle steel tower, to withstand little wind pressure, flexural rigidity, compact structure, large force transfer clear, in harmony with the environment, will be able to bring into full play the bearing performance of steel pipe material, is widely applied in large capacity, long distance transmission line construction. Transmission steel tower bar between the forces is to be transmitted by nodes, the nodes determine the form and structure optimization affect the overall mechanical properties of steel tower. The node destroy often leads to failure of each member, causing the destruction of the whole tower [1][2].

In the electric transmission steel tube tower, the node connection form includes: flange connection, intersecting connection, flapper connection, the flange connections are widely used, and the flange comprises a stiffened flange, non stiffened flange etc.. Stiffened flange is also known as rigid flange, it has high rigidity, high bearing capacity, flange welding workload is heavy due to the welding stiffener, welding residual stress and residual deformation is large influence on mechanical properties of flange; Non stiffened flange is also known as the flexible flange, flange welding workload is decrease without stiffener. At the same time, it has the production of simple, beautiful appearance, and convenient installation, flange flatness can be guaranteed and other characteristics, so the flexible flange is widely used in practical engineering [3]. At present in China has some engineering application. Such as Shanghai's Yang gao - Waigaoqiao - Yang line 500kV double circuit line project,in Jiuquan - Anxi line $750 \mathrm{kV}$ double circuit lines on the same tower project.

Due to the lack of supporting the stiffeners, the flexible flange stiffness is relatively low. When force is larger in the flange, the flange is prone to bending deformation, generating a larger prying force, resulting in uneven stress in bolts and flange damage, which affects the entire tower safety operation in the last.

Therefore, considering the nonlinear contact problem of bolt and flange, this paper selects flexible flange using $500 \mathrm{kV}$ Wusongkou large crossing tower as the finite element simulation model in order to study the mechanical properties of flexible flange [4]. The author verifies that flexible flange of steel tube tower can work safety under design load by simulation in the finite element software 
ANSYS and analyzes the influence of performance of bolts and margins, flange plate thickness, number of bolts and bolt Preload on the mechanical properties of flexible flange.

\section{Finite element model of flexible flange of Steel tube tower}

\section{1finite element model to select}

On the background of $500 \mathrm{kV}$ Wusongkou large span steel tube tower project, a flange model ,which combined with the flexible flange test research of [4] used in engineering, was selected for finite element analysis, the meaning of the parameters is shown in Figure 1, Specific parameters listed in Table 1.

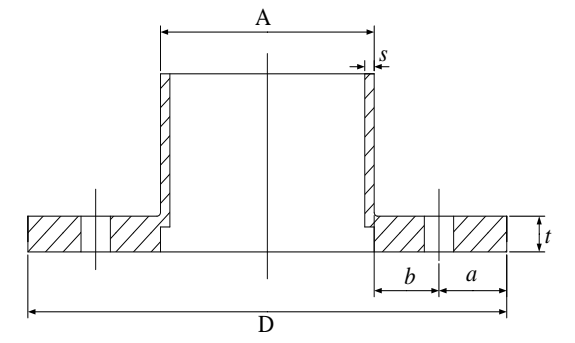

Fig. 1 Schematic of flange parameters
The meanings of some parameters:

$\mathrm{a}=$ distance from bolt to flange plate edge

$\mathrm{b}=$ distance from bolt to circular steel tube

$$
\begin{gathered}
\mathrm{t}=\text { thickness of plates } \\
\mathrm{P}=\text { bolt preload } \\
\mathrm{n}=\text { total number of bolts } \\
\mathrm{D}=\text { flange plate diameter } \\
\mathrm{d}=\text { the diameter of the bolt }
\end{gathered}
$$

\begin{tabular}{|c|c|c|c|c|c|c|}
\hline specimen & Material & "Yield & \multicolumn{3}{|c|}{ Dimension(mm) } & Other parameters \\
\hline Tube & Q345 & 430 & $\overline{\Phi 400 X 6}$ & $\mathrm{~b}=1.55 \mathrm{~d}$ & Design load & $1772 \mathrm{kN}$ \\
\hline Flange plate & Q345 & 340 & $t=24$ & $D=546$ & Bolt preload & $120 \mathrm{kN}$ \\
\hline Bolt & 20MnTiB & 495 & M24 & $a=1.5 d$ & Bolt number & 24 \\
\hline
\end{tabular}

Table 1 Specific parameters of flange

\subsection{The establishment of finite element model}

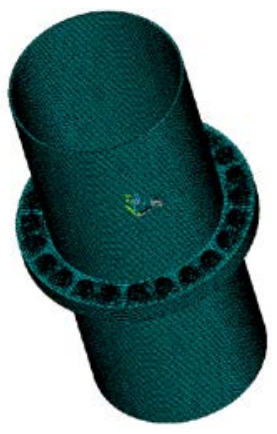

(a) complete pattern

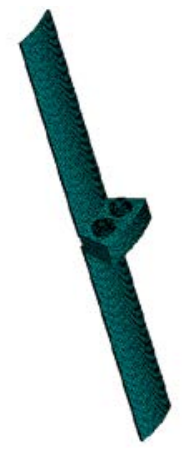

(b)1/12 Flange model

Fig. 2 flange finite element model

According to Table 1 flange parameters, the model for flange based on flange geometry symmetry and axial force characteristic was established to reduce computing time in ANSYS, which was a part of the two bolts on the flange corresponding, namely $1 / 12$ flange model as shown in figure 2 . The stress-strain relationship for flange was taken as bilinear isotropic hardening model. Solid modeling has the following advantages: (1) the stress distribution and deformation diagram in each entity section can be accurately obtained; (2) the mechanical properties of flange can be actually simulated. So SOLID185 solid element was be selected to simulate flexible flange. To simulate the preload of bolts, PREST179 was introduced. The key to simulate the behavior of the connections was to consider the contact problem appropriately. So contact pairs with 3-D target contact elements CONTA 174 and 3-D surface elements TARGE 170 were created contact interfaces of between the flange plates, flange and the bolt and bolt and bolt hole as shown in Fig.3, contact friction coefficient is 0.3. The control of element mesh size and hexahedral shape are advantage to facilitate the calculation. 


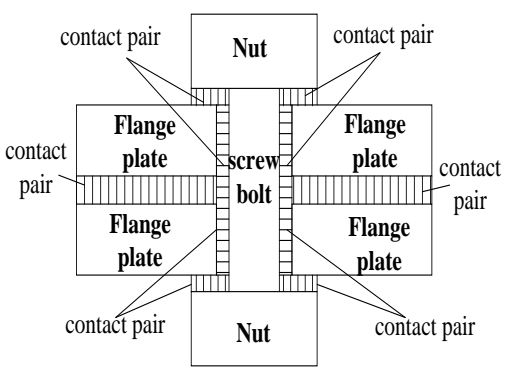

Fig. 3 contact interfaces

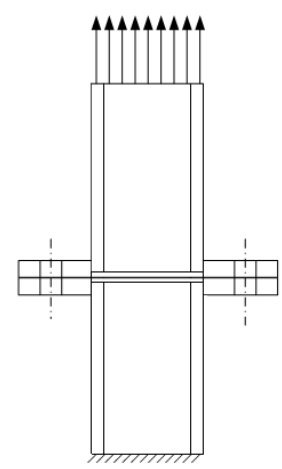

Fig. 4 Schematic model solution

\subsection{Solving the finite element mode}

The model was exactly designed based on the experimental specimens and boundary conditions, freedom of the end of lower tube end is limited to 0 , and axial load was applied on the top of upper tube surface, as shown in figure 4.

In accordance with the flange actual mechanical properties and the research content, 2 kinds of load were applied in the upper tube end. When the flange mechanical properties were studied under axial design tension, axial tension load was applied; when the bearing capacity of flange was studied, displacement load was applied. In order to make the simulation more close to the experiment, the load way used the ramp load, each time load was the total load $10 \%$.The sets were contribute to getting simulation results in order to the following analysis.

\section{Simulation results and analysis}

\subsection{Analysis of flange strength}

Numerical simulation was implemented using finite element method. Finite element model applied to the design load was established by ANSYS software in order to obtain part of the stress results.

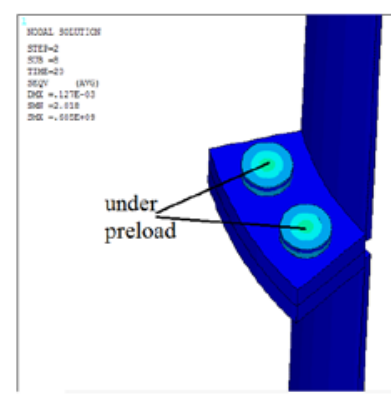

Fig.5. the stress cloud of bolt

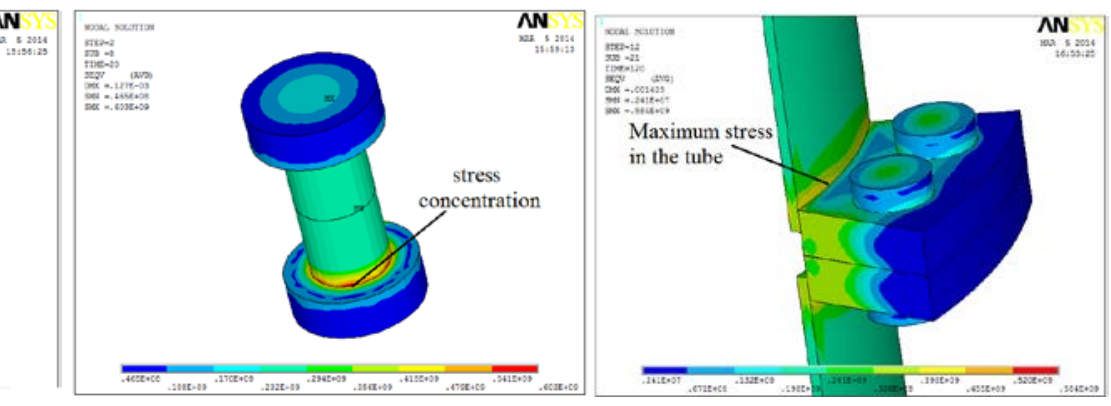

Fig.6. the stress cloud of flange

Preload applied gives a tension bolt along the axial direction of the screw to make the component connect closely in together. After the bolt preload is applied, nut and flange plate contacts and generates a certain compressive stress, Especially the place in the nut and screw connection appears stress concentration, where is the maximum stress(Fig.5). But screw overall stress is uniform distribution without affecting the overall strength of the bolt.

Under the design load, tube and flange plate connection with yellow stress area shows greater stress, where maximum stress is 390MPa.Other tube partial stress value is equally 200MPa, while tube yield strength is $430 \mathrm{MPa}$ (Fig.6). These results indicate that the overall tube is in elastic stage, plastic deformation occurred.

From the current experimental and theoretical analysis[3-5], flange plate prying force always generates under tension. In other words the flange plate inner end is opened under tension axial force, the flange plate outer end tight top since flange plate inner end opened and bolt limited. These results lead to prying force (Fig.7). 


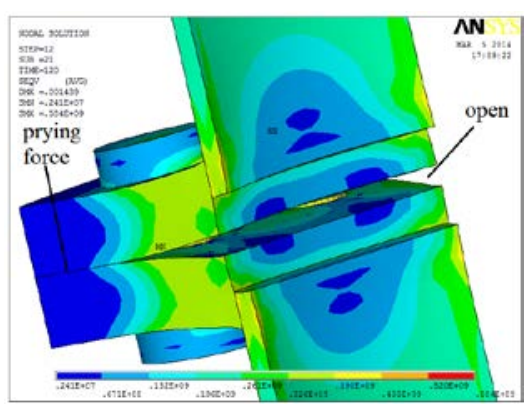

Fig.7 inner end under design load

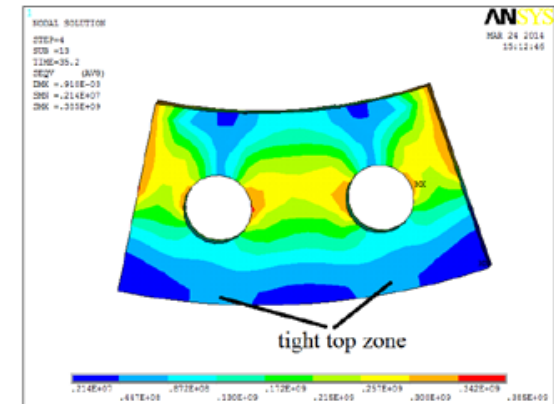

Fig.8 the stress cloud of flange plate

Under the axial design tension load, since the bolt preload force play in restricting the flanges plate deformation, flange plate produces a certain bend deformation in the area between the bolt and tube, the flange plate outer end tight top to generate prying force. This time maximum stress of flange plate occurs at the bolt hole, which is 300MPa, but flange yield strength is 340MPa (Fig.8).The result shows flange plate is in elastic stage.

Since the flange plate inner end is opened, bolts not only withstand the tension, but also withstand the bend, so bolt stress larger area is close to the tube side. Since pressure and tension are superposition in the bolt. The bolt stress near the flange plate outer end is smaller than other parts. Through the bolt stress cloud (Fig.9), the majority of stress in the bolt is smaller than the yield stress in addition to certain parts of stress concentration, which shows the overall bolt is in elastic stage.
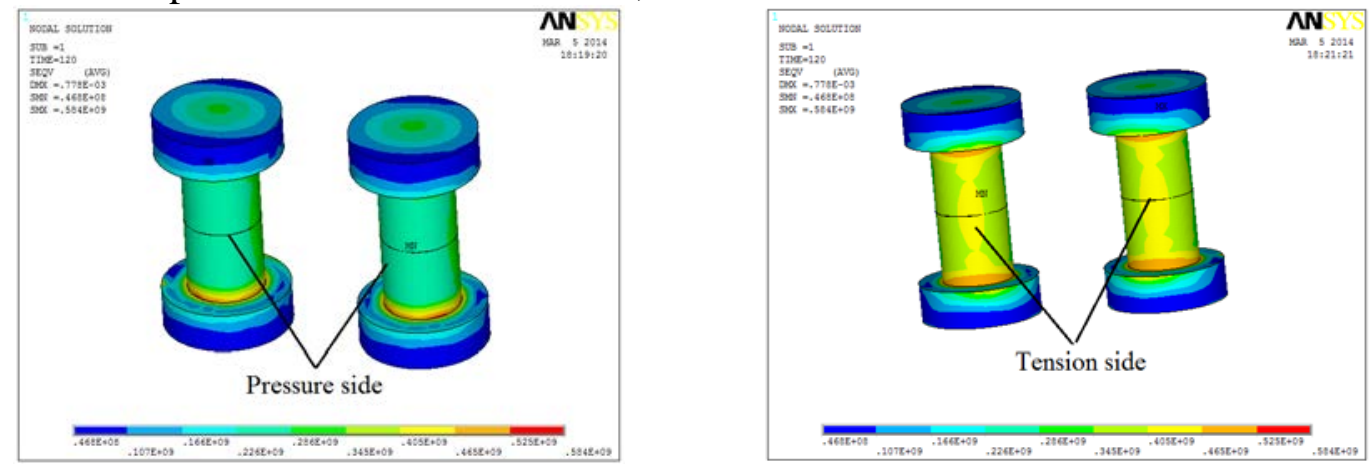

Fig.9. the stress cloud of bolt under design load

\subsection{Bearing capacity analysis of flange model}

Displacement load is $10 \mathrm{~mm}$ in the tube end. Then the load-displacement curve of flange is obtained by using time course post-processing technology of the finite element software (Fig.10).The part of the data about curve is in the Table 2.

When the displacement load gets a certain value, the inflection point of the curve appears in the Fig 10. So the point is regarded as discrimination standard of yield load. Before the inflection point appears, the curve is linear. After the curve is not a linear, these results show that the inflection point is discrimination standard of elastic-plastic deformation. According to fig10 and table 2, the yield load of this point is $2495 \mathrm{kN}$.

Table 2 date of the load-displacement curve

\begin{tabular}{cccc}
\hline $\begin{array}{c}\text { Displacement } \\
(\mathrm{mm})\end{array}$ & $\begin{array}{c}\text { Flange load } \\
(\mathrm{kN})\end{array}$ & $\begin{array}{c}\text { Displacement } \\
(\mathrm{mm})\end{array}$ & $\begin{array}{c}\text { Flange load } \\
(\mathrm{kN})\end{array}$ \\
\hline 0 & 0 & 5 & 3001383 \\
1 & 1230838 & 6 & 3026429 \\
2 & 2209207 & 7 & 3038577 \\
3 & 2754705 & 8 & 3043588 \\
4 & 2939623 & 9 & 3042366 \\
\hline
\end{tabular}




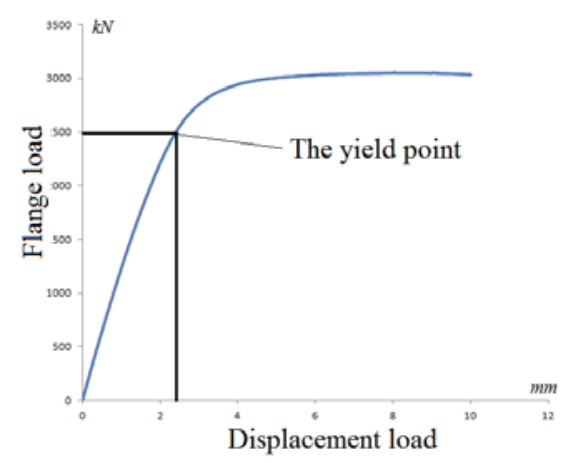

Fig 10 the load-displacement curve of flange

\subsection{Comparison of analytical results and experimental results}

Comparative analysis of finite element results with the experimental results are as follow[4].

Table 3 Comparative of Finite Element Results with the Experimental Results

\begin{tabular}{cccc}
\hline Method & $\begin{array}{c}\text { Flange Plate } \\
\text { stress }(\mathrm{MPa})\end{array}$ & $\begin{array}{c}\text { Flange deformation } \\
(\mathrm{mm})\end{array}$ & $\begin{array}{c}\text { Flange yield } \\
\text { Load(kN) }\end{array}$ \\
\hline Test & 208 & 0.31 & 2385 \\
ANSYS & 220 & 0.269 & 2495 \\
ANSYS/ Test & 1.057 & 0.867 & 1.05 \\
\hline
\end{tabular}

According to ANSYS result and experimental result ratio, the values about flange plate stress and flange yield load are not big. But the values about flange deformation are certain differences. Considering the influence of measurement instruments and experimental environment in the process of test and the finite element software about the flange connection parameters set, the magnitude survey data influence are not big, therefore the deviation is in the allowable range.

Through the comparative analysis, the rationality and correctness of the finite element model of flange are verified. So finite element simulation can replace experimental study on the flange in the situation of excessive specimen and test condition limit.

\section{Effects of parameters on the bearing capacity of flange}

The yield load has been taken as the distinguishing rule of the flange bearing capacity. Actually it is the inflection point of the load-displacement curve. A method of single variable control, which is mean that one parameter is changed each time, was proposed to study the effect of parameters, such as distance from bolt to flange plate edge, distance from bolt to circular steel tube, thickness of plates, bolt preload, and total number of bolts on the flange bearing capacity, respectively. The parameter value is suggested in Table.4, which has calculated a total of 15 flange model .Concrete analysis is as follows:

Table 4 parameters value changed of flange

\begin{tabular}{lccccc}
\hline Parameters & $\mathrm{a}(\mathrm{mm})$ & $\mathrm{b}(\mathrm{mm})$ & $\mathrm{t}(\mathrm{mm})$ & $\mathrm{p}(\mathrm{kN})$ & $\mathrm{n}$ \\
\hline Specific & 31 & 32 & 20 & 10 & 18 \\
Value & 36 & 37 & 24 & 120 & 20 \\
& 41 & 42 & 26 & 220 & 24 \\
\hline
\end{tabular}

\subsection{Effect of distance "a" from bolt to plate edge}

The 3 load-displacement curves suggested in Fig.11 reflect the effect of the value "a" of the distance from bolt to flange plate edge on the flange bearing capacity. The load value corresponding to inflection points of these curves is $2495 \mathrm{kN} 、 2484 \mathrm{kN}$ and $2502 \mathrm{kN}$. That is, 3 curve inflection points are almost coincidence. It indicates that different value of "a” has a little effect on the flange bearing capacity. 


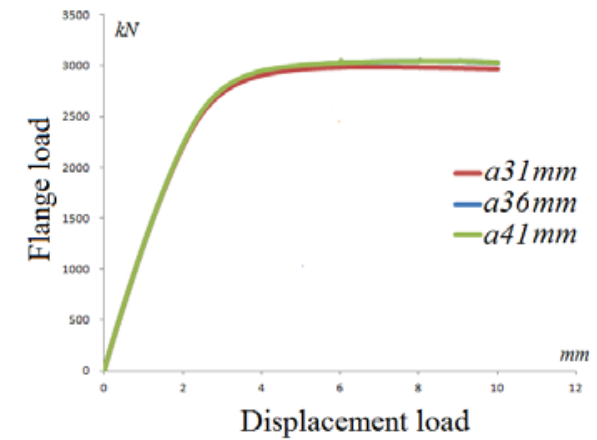

Fig.11 Effect of distance from bolt to flange plate edge tube

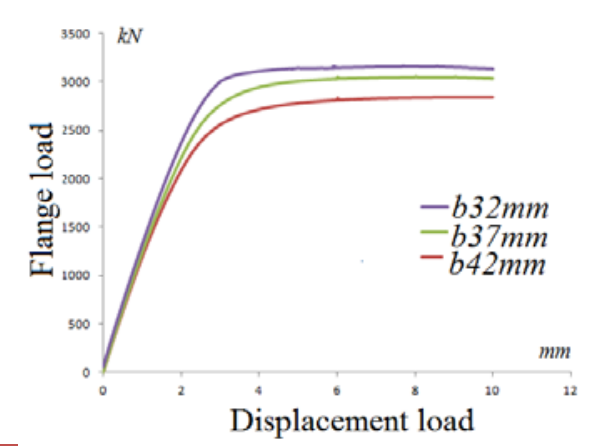

Fig.12 Effect of distance from bolt to

\subsection{Effect of distance "b" from bolt to circular steel tube}

As can be seen from the curve trend, with the decreasing values of "b", in the curve linear changing phase, that is, e, the change rate of the flange displacement curve is greater in the curve linear changing phase (the flange is at the elastic stag). Meanwhile compared to specimen b42, the bearing capacity of b32 and b37 has respectively increased by $11.4 \%$ and $19.7 \%$. It indicates that the work of controlling the deformation of flange and limiting the additional moment at the edge of the flange is more obvious with the bolt to circular steel tube being closer.

\subsection{Effect of thickness " $t$ " of flange plate}

The 3 curves suggested in Fig.13 shows curves of bearing capacity of changes different curves flange thickness. With the increasing thickness of the flange, the rate of change increases in the linear portion of the curve. Compared to specimen t20, the bearing capacity of t24 and t26 has increased by $10.4 \%$ and $16.0 \%$, respectively. It indicates that, as the flange thickness increases, the stiffness and the flange bearing capacity increase accordingly. While, considering the economic benefits, the flange thickness should not be too large.

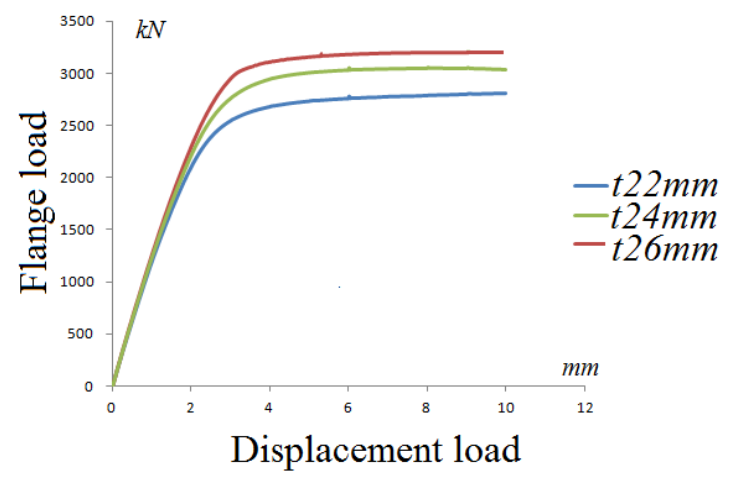

Fig.13 Effect of thickness of flange plat

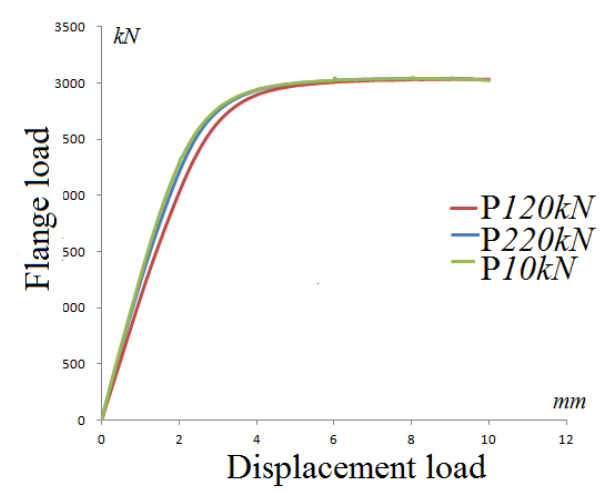

Fig.14 Effect of high-strength bolt preload

\subsection{Effect of bolt preload "P”}

According to suggest curves in Fig.14 that, the bearing capacity of these flanges all are $2495 \mathrm{kN}$ when preload applied for high-strength bolts. However, as can be seen from the graph, with the increase of preload, the initial stiffness of P220 and P120 specimens compared to P10 to increase by $12.7 \%$ and $8 \%$,. It indicated that the preload is increased can improve the flange initial rigidity and limit its deformation to a certain extent.

\subsection{Effect of bolt number " $n$ "}

With the increase of the bolt number, the slope of the curve increases in the curve linear changing phase which changes the location of inflection point in the Fig 15. The stiffness of N24 and N20 specimen compared with N18specime respectively increases by $12.1 \%$ and $11 \%$, the bearing capacity of N24 and N20 specimen compared with N18specime respectively increases by $21.9 \%$ and $41.8 \%$, Because of the increased number of bolt, flange deformation will be limited, which is equivalent to 
improve the flange joint stiffness and improve the bearing capacity of flange. The increasing the number of flange bolts can make mechanical properties of flange more uniform at the same time.

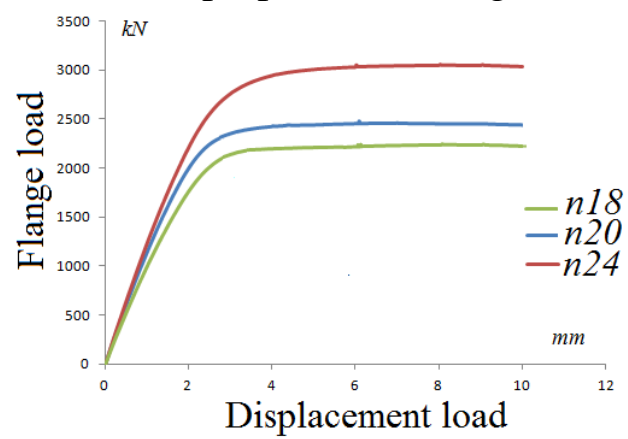

Fig. 15 Effect of the number of flange high strength bolt

\section{Conclusion}

Based on nonlinear theory,a flexible flange recommended by $500 \mathrm{kV}$ Wusongkou large crossing tower was set an example to simulate and analyze, then the bearing capacity curve of different flanges was analyzed. Several Conclusions are drawn as follows.

(1) On the basis of the results of Numerical simulation of flange strength, the analysis shows that flange is in the stage of elastic deformation under the design load, flange and high strength bolt have a certain strength reserve.

(2) The flange plate inner end is opened and outer end tights top under axial tension, which leads to generate prying force in the flange plate. At the same time, the zone near the bolt hole has a certain stress concentration.

(3) According to study the effect of the flange parameters, some methods to improve the bearing capacity of flexible flange, such as by arranging bolt closer to the tube, increasing the flange thickness and the number of bolts in flange plate.

(4) When changing the distance from bolts to flange edge, there will be a small effect on the bearing capacity of the flange, but the overall size of the flange plate can be controlled to a certain extent, which contributes to reduce the overall weight of the flange.

\section{References}

[1] Zhusen Sun, Yongfeng Cheng, Qiang Zhang, et al. Application and dissemination of steel tubular tower in transmission lines [J]. Power system Technology, 2010:

34(6): 186-192. (in Chinese).

[2] Jingbo YANG, Maohua LI, Feng-li YANG, Junke HAN.New advances in the study of transmission tower structure of china [J].Power system Technology, 2008:

32(22): 77-83. (in Chinese).

[3] Chixin Wang, Hao Wang. Preliminary analysis of flexible flange connection[J]. Steel Construction, 2009, 24(10):10-15. (in Chinese)

[4] Weichen Xue, Yongjia Huang, Guinian Wang. Prototype experimental studies on flexible flanges for long-span electric transmission tower in wusongkou[J]. Industrial Construction, 2004,34( 3) : 68-70

[5] Chuqing WANG, Yonghua GUO, Qing SUN, Bin ZHANG. Experimental and numerical analyses on the ultimate bearing capacity of Q690 flange joint used in steel tube towers[J]. Engineering mechanics, 20013, 30(3):206-213. (in Chinese)

[6] HaiboChen, ChanghuaHe, Zhenfu Li, Haijun Xing.Test and study on calculation method of steel tube non-stiffened flange[J]. Electric Power Constructionn, 2005, 26(7):16-19. (in Chinese)

[7] Zhan GAO, Huan YU, Hua LI.FE analysis of rigid and flexible flanges in $500 \mathrm{kv}$ substation trusses[J]. Industrial Construction, 2008, 29( 2) : 32-36. 
[8] DL/T 5154-2002, Technical regulation of design for tower and pole structures of over head transmission line[S]. Beijing: China Electric Power Press, 2002. (in Chinese) 